\title{
DIGNIDAD HUMANA Y PRINCIPIO "PRO HÓMINE" EN LOS LITIGIOS SOBRE DERECHOS HUMANOS
}

Carlos E. Delpiazzo *

\begin{abstract}
RESUMEN. En el Estado Constitucional de Derecho, la relación entre la persona y el Estado cada vez más se funda en la centralidad de la primera, que encuentra su fundamento en la dignidad humana y que proyecta consecuencias en todas las dimensiones de la vida humana (individual, social y trascendente). Siendo así, es indiscutible la relevancia del principio «pro hómine» para la resolución de los litigios en los que están en juego los derechos humanos. Particularmente, reviste especial interés la proyección de dicho principio en los deberes de la Administración cuyo ser y obrar se sustentan en la esencial servicialidad que la caracteriza.
\end{abstract}

PALABRAS CLAVES. Dignidad humana. Principio "pro hómine». Servicialidad administrativa. Centralidad de la persona. Dimensiones de la personalidad

\begin{abstract}
In the Constitutional Rule of Law, the relationship between the individual and the State is increasingly based on the centrality of the former, which finds its foundation in human dignity and that projects its consequences in all dimensions of human life (personal, social and transcendental). In this context, the relevance of the pro homine principle is unquestionable for the purposes of the resolution of disputes involving human rights. The projection of such principle over the Administration's duties is particularly interesting, considering that the Administration exists and acts pursuant to its characteristic essential services.
\end{abstract}

KEY WORDS. Human Dignity. Pro Homine Principle. Administrative Services. Centrality of the Individual. Dimensions of Personality.

* Doctor en Derecho y Ciencias Sociales por la Universidad Mayor de la República Oriental del Uruguay. Director de la Escuela de Posgrado de la Facultad de Derecho de dicha Universidad. Catedrático de Derecho Administrativo en la Facultad de Derecho de la Universidad de Montevideo.Vicepresidente del Instituto Internacional de Derecho Administrativo y Secretario General del Foro Iberoamericano de Derecho Administrativo. Correo electrónico: carlos.delpiazzo@delpiazzo.com 


\section{INTRODUCCIÓN}

La conmemoración del 70 aniversario de la Declaración Universal de Derechos Humanos es ocasión más que propicia para reflexionar acerca de la importancia de los principios que rodean a la dignidad humana cuando se trata de resolver conflictos en los que están en juego los derechos edictados en dicha Declaración.

En la medida que el Derecho se construye no sólo a partir de normas sino también del principios, en los litigios en que aparecen en juego derechos fundamentales -especialmente los que involucran a las Administraciones públicas- es preciso mirar con nuevo enfoque lo que tradicionalmente hemos llamado la relación jurídico administrativa.

En ella, la centralidad de la persona humana y la servicialidad de la Administracion son como las dos caras de una misma moneda, o los dos términos de una ecuación fundamental.

En efecto, lo propio del Estado constitucional de Derecho, que impregna todo el Derecho Administrativo contemporáneo, es el reconocimiento de la primacía de la persona humana, derivada de su eminente dignidad, de la que se desprenden todos y cada uno de los derechos fundamentales y desde la cual deben ellos interpretarse y aplicarse: el legislador, absteniéndose de sancionar leyes que los contravengan; el juez al dirimir los litigios sometidos a su jurisdicción, y cualquier autoridad administrativa al cumplir sus cometidos ${ }^{1}$.

Siendo así, adquiere singular relevancia la servicialidad de la Administración, no sólo como cualidad inherente a su ser y quehacer -administración quiere decir servicio tanto en sentido subjetivo cuanto objetivo- sino como correlato justificante de su propia existencia, a la cual no es ajena el principio "pro hómine". Cada vez más la jurisprudencia acude a estos aspectos.

\section{CENTRALIDAD DE LA PERSONA HUMANA}

\section{La dignidad humana como fundamento}

Desde el punto de vista conceptual, la centralidad de la persona -"protagonismo originario" lo llamaba Mariano BRITO ${ }^{2}$ - como destinataria del quehacer estatal y foco para la interpretación de las relaciones emergentes es la lógica consecuencia de que, cualquiera sea su edad o normalidad, el hombre ostenta una dignidad que le viene no de ser un hombre de dignidad sino de tener la dignidad de un hombre; de esa dignidad eminente o intrínseca extraen su razón de ser los derechos humanos, cuyo titular no es la humanidad en su abstracción genérica ni un determinado tipo de hombre sino cada hombre en su personal concreción ${ }^{3}$.

${ }^{1}$ Carlos E. DELPIAZZO - "Derecho Administrativo General" (A.M.F., Montevideo, 2015), volumen 1, segunda edición actualizada y ampliada, pág. 89 y sigtes.

${ }_{2}^{2}$ Mariano R. BRITO - "Libertad y autoridad del Estado", en A.A.V.V. - "Aspectos legales y socioeconómicos de la desregulación y privatización" (F.C.U., Montevideo, 1991), pág. 28; y en "Derecho Administrativo. Su permanencia, contemporaneidad, prospectiva" (U.M., Montevideo, 2004), pág. 245.

${ }^{3}$ Arturo ARDAO - "El hombre en cuanto objeto axiológico", en "El hombre y su conducta. Ensayos filosóficos en honor de Risieri Frondizi” (UPRED, Buenos Aires, 1980), págs. 73 y 74. 
Desde la perspectiva del Derecho Administrativo, cabe suscribir la enseñanza de Jesús GONZALEZ PEREZ en el sentido de que la dignidad de la persona actúa "como principio informador y límite de la actividad administrativa" ya que "es incuestionable que cualquiera que sea la finalidad perseguida por la Administración, cualquiera que sea la forma de actuación y cualquiera que sea la realidad social sobre que recaiga, ha de respetar como algo sagrado e inviolable la dignidad de la persona" ${ }^{4}$.

Es que la dignidad humana es intangible y de máximo valor no por imperio de disposición alguna sino por el origen y naturaleza del hombre, impregnando, por tanto, todas las ramas del Derecho ${ }^{5}$ e incidiendo en la recta jurisprudencia sobre los derechos humanos ${ }^{6}$.

Con palabras de José Aníbal CAGNONI, "la dignidad es consideración, respetabilidad, estimación de cada uno por sí y con respecto a todos los demás, es lo que merece la persona por su humanidad, es lo adecuado a esta esencialidad que hace singular en el universo a esta especie de seres vitales que somos los humanos" 7 .

Desde el punto de vista jurisprudencial, cada vez es más frecuente invocar esa dignidad como cualidad inherente a toda persona dotada de fin propio y no como un simple medio para los fines de otros.

Así, en México, el Tribunal Pleno de la Suprema Corte de Justicia de la Nación ha dicho que "la dignidad del hombre es inherente a su esencia, a su ser. Se trata del reconocimiento de que en el ser humano hay una dignidad que debe ser respetada en todo caso, pues se trata del derecho a ser considerado como ser humano, como persona, es decir, como ser de eminente dignidad. Es un derecho absolutamente fundamental para el ser humano, base y condición de todos los demás: el derecho a ser reconocido siempre como persona humana. Así, de la dignidad humana se desprenden todos los demás derechos, en cuanto son necesarios para que el hombre desarrolle integralmente su personalidad" 8 .

Del mismo modo, en Argentina, la Corte Suprema de Justicia de la Nación ha dicho que "la dignidad del ser humano no deriva de un reconocimiento ni de una gracia de las

${ }^{4}$ Jesús GONZALEZ PEREZ - "La dignidad de la persona humana y el Derecho Administrativo" (Jurua, Curitiba, 2007), pág. 13.

5 Mariana BLENGIO VALDES - "El derecho al reconocimiento de la dignidad humana" (A.M.F., Montevideo, 2007), pág. 55 y sigtes.; Néstor SAGÜES - "Dignidad de la persona e ideología constitucional", en Rev. de Derecho Constitucional y Político (Montevideo, 1996), tomo XII, Nº 72, pág. 679 y sigtes.; Ricardo Francisco SECO - "Un contenido para los términos dignidad de la persona humana. Aportes desde el Derecho del trabajo y el pensamiento social cristiano", en Rev. Derecho Laboral (Montevideo, 2010), tomo LIII, N 239, pág. 459 y sigtes.; y Raúl CERVINI - "El Derecho penal del enemigo y la inexcusable vigencia del principio de la dignidad de la persona humana”, en Rev. de Derecho. Publicación arbitrada de la Universidad Católica del Uruguay (Montevideo, 2010), $\mathrm{N}^{\circ} 5$, pág. 36.

${ }^{6}$ Mariano R. BRITO - "La dignidad humana como fundamento de nuestro Derecho Administrativo", en Carlos E. DELPIAZZO (Coordinador) - "Pasado y presente del Derecho Administrativo Uruguayo" (F.C.U., Montevideo, 2012) pág. 165 y sigtes.; Mariana BLENGIO VALDES - "El derecho al reconocimiento de la dignidad humana" cit., pág. 63 y sigtes; y José CHAVEZ FERNANDEZ POSTIGO - "La dignidad como fundamento de los derechos humanos en las sentencias del Tribunal Constitucional peruano" (Palestra, Lima, 2012).

${ }^{7}$ José Aníbal CAGNONI - "La dignidad humana. Naturaleza y alcances", en CATEDRA UNESCO DE DERECHOS HUMANOS - "Dignidad Humana” (Montevideo, 2003), pág. 65.

${ }^{8}$ Sentencia del Tribunal Pleno de la Suprema Corte de Justicia de los Estados Unidos Mexicanos de 6 de enero de 2009. 
autoridades o poderes, toda vez que resulta intrínseca o inherente a cada una de las personas y por el solo hecho de serlo" 9 .

En reiterados pronunciamientos, la Corte Suprema de Justicia de Costa Rica ha entendido que "El ser humano, por el solo hecho de serlo, por haber nacido tal, es depositario de una serie de derechos que le son reconocidos en protección de su dignidad" ${ }^{10}$.

En Uruguay, es criterio firme de la Suprema Corte de Justicia que "Todos los seres humanos son libres y son iguales en dignidad y derechos desde que nacen. La dignidad no es pues un derecho que se conquista como una suerte de patrimonio moral sino que se sustancia de la individualidad" ${ }^{11}$.

\section{Proyección de la dignidad en las dimensiones de la vida humana}

Al menos desde Aristóteles, es lugar común destacar que el hombre tiene una dimensión individual y una dimensión social, que conlleva la política sin confundirse con ella, a las que corresponde agregar una dimensión trascendente, siendo todas inescindibles entre sí porque la persona humana es una sola ${ }^{12}$.

Por lo que refiere a la dimensión individual, surge de lo antedicho que los derechos fundamentales lo son por derivar de la naturaleza del hombre, de modo que la fuente de los mismos radica en su eminente dignidad humana ${ }^{13}$.

Ya la legislación de Partidas reconocía que "La persona del home es la más noble cosa del mundo" (Ley 26 de Partida VII, Título I), precepto que el proverbio castellano tradujo por "Nadie es más que nadie" para poner de manifiesto que la supremacía del ser humano se manifiesta en que todos los hombres son iguales en dignidad ${ }^{14}$.

En Uruguay, así lo proclama expresamente el art. 72 de la Constitución cuando explicita que "La enumeración de derechos, deberes y garantías hecha por la Constitución no excluye los otros que son inherentes a la persona humana" ${ }^{15}$.

${ }^{9}$ Sentencia de la Corte Suprema de Justicia de la Nación de 21 de setiembre de 2004.

${ }^{10}$ Sentencia de la Corte Suprema de Justicia de Costa Rica, Sala Constitucional, de 20 de marzo de 2009.

${ }^{11}$ Sentencia de la Suprema Corte de Justicia N 88 de 8 de diciembre de 1993.

${ }^{12}$ Carlos E. DELPIAZZO - "Las dimensiones del administrado", en "Jornadas en homenaje al Prof. Dr. Mariano R. Brito organizadas por el Anuario de Derecho Administrativo” (U.M., Montevideo, 2014), pág. 227 y sigtes.; y "Derecho Administrativo General" (A.M.F., Montevideo, 2017), volumen 2, segunda edición actualizada y ampliada, pág. 228 y sigtes.

${ }^{13}$ Mariano R. BRITO - "La dignidad humana como fundamento de nuestro Derecho Administrativo" cit., pág. 155 y sigtes.

14 Jesús GONZALEZ PEREZ - "La dignidad de la persona” (Civitas, Madrid, 1986), pág. 24.

${ }^{15}$ Héctor GROS ESPIELL - "La dignidad humana en los instrumentos internacionales de derechos humanos", en CATEDRA UNESCO DE DERECHOS HUMANOS - "Dignidad Humana" (Montevideo, 2003), pág. 9 y sigtes.; José Aníbal CAGNONI - "La dignidad humana. Naturaleza y alcances", en Rev. de Derecho Público (Montevideo, 2003), Nº 23, pág. 11 y sigtes., y "La primacía de la persona: el principio personalista”, en Rev. de Derecho Público (Montevideo, 2004), Nº 24, pág. 135 y sigtes.; María Elena ROCCA - "Toda nuestra Constitución reposa sobre la noción de persona”, en Rev. de Derecho Público (Montevideo, 2004), N 24, pág. 139 y sigtes.; y Marcelo LABORDE - "No sólo de derechos vive el hombre. Los deberes de las personas en el artículo 72 de nuestra Constitución", en Carlos E. DELPIAZZO (Coordinador) - "Pasado y presente del Derecho Administrativo Uruguayo" (F.C.U., Montevideo, 2012), pág. 185 y sigtes. 
Con palabras de Alberto Ramón REAL, "Inherente significa que por su naturaleza está de tal manera unido a otra cosa que no se puede separar", de modo que "derechos inherentes a la personalidad humana son pues, aquellos inseparables por su naturaleza de dicha personalidad, de los que se goza por el solo hecho de ser hombres" ${ }^{16}$.

Consecuentemente, todos los derechos inherentes a la condición humana se imponen no sólo al legislador sino también al constituyente por cuanto preexisten a la organización estatal; no son creados por acto jurídico alguno sino que nacen con el hombre mismo, cualquiera sea su condición, sea varón o mujer, joven o viejo, enfermo o sano, cualquiera sea su raza, religión o ideología.

En cuanto a la dimensión social, es evidente que "El hombre no es sólo en tanto que individuo, en dimensión de interioridad; se abre a los otros, formando el nosotros, o, inevitablemente, se mutila y empobrece, y aún se destruye... Por exigencia racional no puede alcanzar su perfección solo; reclama la apertura, referencia y vinculación a los demás" ${ }^{17}$ en diversos ámbitos.

Entre ellos, merece destaque en primer lugar la familia ya que el hombre es inconcebible sin relaciones familiares. Por eso, la generalidad de la doctrina destaca que la importancia de la familia es enorme en la vida social y política de los países como institución interpuesta como entidad autónoma entre el individuo y el Estado destinada a generar vida y preparar para vivirla ${ }^{18}$.

Es que la familia es una comunidad de personas ligadas por una unidad de origen: todo hombre es hijo y nunca deja de serlo. Ser hijo es incluso más radical que ser varón o mujer, porque indica el modo de originarse uno mismo: nacer. Ser hijo significa depender, proceder de, tener un origen determinado, reconocible en nombres y apellidos: es la estirpe a la que uno pertenece ${ }^{19}$.

Por lo tanto, la familia es una institución natural y permanente, que constituye lo que Adolfo GELSI BIDART llamó con acierto “ellugar de la persona” " ${ }^{20}$. En la familia se aprende a vivir y se obtiene un perfil genético propio, tanto en lo físico como en lo psíquico (carácter, aptitudes, urdimbre afectiva, aprendizaje de conducta, costumbres, gestos, modos de hablar, cultura práctica, etc.). Pero además, la familia es el depósito de los valores que más profunda y permanentemente quedan grabados en el espíritu de sus miembros mediante la educación (actitudes religiosas, virtudes morales, modos de valorar, ideales, etc.).

De ahí el indiscutible valor de la familia, y de ahí también el sólido fundamento de su ser y existir perdurable que las Constituciones reconocen con expresiones tales como "base", "fundamento", "núcleo fundamental", "elemento natural y fundamental", que califican la importancia y situación de primacía de la familia.

En segundo lugar, la producción y la obtención de los medios necesarios para satisfacer necesidades mediante la técnica y el trabajo encuentran su expresión en la empresa,

\footnotetext{
16 Alberto Ramón REAL - "Los principios generales de Derecho en la Constitución uruguaya" (Montevideo, 1965), pág. 24.

${ }_{17}$ Mariano R. BRITO - "Derecho Administrativo. Su permanencia, contemporaneidad, prospectiva" cit., págs. 59 y 60 .

${ }^{18}$ Carlos E. DELPIAZZO - "Dignidad humana y Derecho" (U.M., Montevideo, 2001), pág. 37 y sigtes.

${ }^{19}$ Ricardo YEPES STORK - "Fundamentos de Antropología” (EUNSA, Pamplona, 1996), págs. 285 y 286.
} 
entendida genéricamente como la organización de capital y trabajo destinada a la producción o mediación de bienes o servicios.

La naturaleza social del hombre lo llevó muy pronto a descubrir las ventajas que aporta la coordinación de varios individuos y la utilización de instrumentos apropiados, conforme a un plan, para alcanzar los propósitos perseguidos.

Independientemente de la diversidad de formas jurídicas que puede adoptar, la empresa es una institución integrada por personas, bienes materiales e inmateriales, puesta al servicio del interés común en el resultado económico pretendido ${ }^{21}$.

En tercer lugar, es preciso añadir que familia y empresa no agotan el elenco de manifestaciones de la dimensión social del hombre, existiendo otras comunidades intermedias que las personas pueden formar en ejercicio de su derecho de asociación y que conlleva el derecho a la institucionalización de la asociación ${ }^{22}$.

En cuarto lugar, es preciso destacar que se habla de comunidades intermedias para diferenciarlas de la sociedad como colectividad jurídicamente organizada en el Estado, como expresión mayor de la dimensión social de los seres humanos ${ }^{23}$, dentro de cuyo ámbito se desarrolla la Administración como organización servicial que tiene a su cargo, como actividad primordial, el ejercicio de la función administrativa ${ }^{24}$.

Respecto a la dimensión trascendente, con independencia de convicciones religiosas o posturas ideológicas, es una realidad evidente que la persona humana tiene un espíritu, aspecto en el cual se diferencia de todos los demás seres vivos.

Como tal, tiene una conciencia o espacio interior al que nadie puede acceder si uno no quiere y que permite a cada hombre direccionar su conducta sin que ningún cautiverio o castigo sea capaz de suprimirle ese nivel de libertad interior para sostener una creencia, pensamiento o deseo ${ }^{25}$.

A partir de la libertad de conciencia queda claro que cada ser humano es la fuente de su actuar, de la que derivan los derechos a la libertad de expresión, a la libre discusión en la búsqueda de la verdad, a la libertad religiosa (que incluye no sólo creer sino también practicar), a vivir según el dictado de las propias convicciones y, en definitiva, a realizar el proyecto vital que cada uno elija.

De ahí la importancia vital en el Estado constitucional de Derecho de la objeción de conciencia como derecho fundamental a incumplir un deber jurídico por motivos de

${ }^{20}$ Adolfo GELSI BIDART - "La familia y el Derecho", en Américo PLA RODRIGUEZ y Ana María RANZETTI (Coordinadores) - "El Derecho y la Familia” (F.C.U., Montevideo, 1998), pág. 248.

${ }^{21}$ Carlos E. DELPIAZZO - "Derecho Administrativo Especial” (A.M.F., Montevideo, 2010), volumen 2, segunda edición actualizada y ampliada, pág. 483 y sigtes.

${ }^{22}$ Horacio CASSINELLI MUÑOZ - "Libertad de asociación, personalidad jurídica y Poder Ejecutivo", en Rev. Derecho, Jurisprudencia y Administración, tomo 65, pág. 273 y sigtes.

${ }^{23}$ Carlos E. DELPIAZZO - "Derecho Administrativo General" cit., volumen 1, segunda edición actualizada y ampliada, pág. 29 y sigtes.

${ }^{24}$ Carlos E. DELPIAZZO - "Derecho Administrativo Uruguayo" (Porrúa - UNAM, México, 2005), pág. 7 .

25 Carlos E. DELPIAZZO - "Derecho Administrativo General" cit., volumen 2, segunda edición actualizada y ampliada, pág. 234 y sigtes. 
conciencia ya que de nada valdría la libertad de conciencia si no se la pudiera hacer valer en el momento en que ella es vulnerada ${ }^{26}$.

Como bien se ha dicho, recordando los ejemplos de Sócrates, Antígona y Tomás Moro, "violentar la conciencia es la peor afrenta que puede inferirse a un ser humano, ya que allí radica lo más esencial de su ser. No están en juego valores de enorme importancia, tales como la libertad física, la propiedad o aún la vida, sino algo aún más esencial: la libertad de ser lo que cada uno piensa que está llamado a ser. Sin eso, se estará encarcelado aún libre, se estará despojado aún rico, se estará muerto aún vivo" ${ }^{27}$.

\section{TRASCENDENCIA DEL PRINCIPIO "PRO HÓMINE" EN EL OBRAR ADMINISTRATIVO}

\section{La servicialidad como fundamento}

Desde el punto de vista conceptual, ya ha quedado dicho que la contracara de la centralidad de la persona humana es la servicialidad de la Administración, que proviene de su propia etimología ya que la palabra "administrar" proviene del latín "ad" y "ministrare", que significa "servir a" ${ }^{28}$.

Quiere decir que el fundamento y la justificación de la existencia de la Administración radica en su servicialidad ${ }^{29}$ y se realiza concretamente en el servicio a la sociedad como tal y en cada uno de sus integrantes y grupos intermedios, de lo que deriva su naturaleza instrumental ${ }^{30}$ a fin de que los componentes del cuerpo social -todos- puedan alcanzar plenamente sus fines propios.

Tal carácter de servicialidad adquiere especial importancia al presente, cuando, con el advenimiento del Estado constitucional de Derecho, "está reapareciendo la idea de que el Estado está para fomentar, promover y facilitar que cada ser humano pueda desarrollarse como tal a través del pleno ejercicio de todos y cada uno de los derechos humanos. Por tanto,

${ }^{26}$ Rafael NAVARRO VALLS y Javier MARTINEZ TORRON - "Conflictos entre conciencia y ley (Iustel, Madrid, 2012), $2^{a}$ edición revisada, pág. 29 y sigtes.; Juan G. NAVARRO FLORIA - "El derecho a la objeción de conciencia" (Abaco, Buenos Aires, 2004); Juvenal M. JAVIER - "Reflexiones sobre la objeción de conciencia e ideario en el Uruguay a partir las leyes $\mathrm{N}^{\circ} 18.987$ y 18.473", en Rev. de Derecho Público (Montevideo, 2013), N 43, pág. 33 y sigtes.; Bruno BERCHESI - "Objeción de conciencia. ¿Sabemos qué significa?”, en Rev. Jurídica La Ley Uruguay (Montevideo, 2010), Año III, Nº 3, pág. 446 y sigtes.; y Marta HANNA - "Recepción jurisprudencial de la objeción de conciencia", en Rev. de Derecho. Publicación arbitrada de la Universidad Católica de Uruguay (Montevideo, 2015), N 12, pág. 217 y sigtes.

${ }^{27}$ Alberto M. SANCHEZ - "La objeción de conciencia en el agente estatal", en Víctor HERNANDEZ MENDIBLE - "Desafíos del Derecho Administrativo Contemporáneo. Conmemoración Internacional del Centenario de la Cátedra de Derecho Administrativo en Venezuela” (Paredes, Caracas, 2009), tomo I, pág. 283 y sigtes.

${ }_{28}$ Carlos E. DELPIAZZO - "Derecho Administrativo General" cit., volumen 1, segunda edición actualizada y ampliada, pág. 59; y "Derecho Administrativo Uruguayo” cit., pág. 7.

${ }^{29}$ Eduardo SOTO KLOSS - "Derecho Administrativo" (Editorial Jurídica de Chile, Santiago, 1996), tomo I, pág. 83 y sigtes.; y "La primacía de la persona humana, principio fundamental del Derecho público chileno", en Estudios Jurídicos en memoria de Alberto Ramón Real (F.C.U., Montevideo, 1996), pág. 507 y sigtes.

${ }^{30}$ Mariano R. BRITO - "Principio de legalidad e interés público en el Derecho positivo uruguayo", en La Justicia Uruguaya, tomo XC, sección Doctrina, pág. 11 y sigtes., y en "Derecho Administrativo. Su permanencia, contemporaneidad, prospectiva” cit., pág. 259 y sigtes. 
el ser humano, la persona, es el centro del sistema; el Estado está a su servicio y las políticas públicas también" ${ }^{31}$.

Es que "El Estado de Derecho viene a configurarse-definirse conceptualmente por su finalidad: concurrir a la realización del hombre en plenitud mediante la función estatal protectora de la persona humana. Es regla paradigmática del Estado de Derecho la aceptación de una sustancia impenetrable para el Estado: la dignidad personal del hombre, que en su interioridad se desenvuelve y cuya protección necesaria (la libertad exterior) plantea el reclamo de tutela" ${ }^{32}$.

Desde el punto de vista jurisprudencial, esa servicialidad ha sido puesta de manifiesto, por ejemplo, respecto a los llamados derechos de prestación, que suponen el obrar administrativo para el logro del bien común, en tanto implica el conjunto de condiciones de la vida social que hacen posible a todos y a cada uno el logro más pleno y más fácil de la propia perfección.

Así, a juicio del Tribunal Constitucional del Perú, "en el Estado social y democrático de Derecho, la ratio fundamentalis no puede ser privativa de los denominados derechos de defensa, es decir, de aquellos derechos cuya plena vigencia se encuentra, en principio, garantizada con una conducta estatal abstencionista, sino que es compartida también por los derechos del prestación que reclaman del Estado una intervención concreta, dinámica y eficiente, a efectos de asegurar las condiciones mínimas para una vida acorde con el principio-derecho de dignidad humana" ${ }^{33}$.

En términos similares, ha dicho el mismo Tribunal que "Bajo este principio [de dignidad humana] el Estado no sólo actuará respetando la autonomía del individuo y los derechos fundamentales como límites para su intervención-obligaciones de no hacer-sino que deberá proporcionar, a su vez, los cauces mínimos para que el propio individuo pueda lograr el desarrollo de su personalidad y la libre elección de sus planes de vida -obligaciones de hacer- ${ }^{34}$ ".

En Argentina, invocando específicamente el principio "pro hómine", la Corte Suprema de Justicia de la Nación ha sostenido que la aplicación e interpretación de las normas debe orientarse hacia la solución que proteja en mayor medida a la persona ${ }^{35}$.

\section{Proyección del principio "pro hómine" en los deberes de la Administración}

Como ya lo he señalado antes de ahora, el formulado como principio "pro hómine" se dirige no sólo al juez sino también a la Administración y su eficacia aplicativa es de gran

${ }^{31}$ Jaime RODRIGUEZ-ARANA MUÑOZ - "Etica, Poder y Estado” (RAP, Buenos Aires, 2004), pág. 75.

${ }^{32}$ Mariano R. BRITO - "El Estado de Derecho en una perspectiva axiológica”, en Rev. Ius Publicum (Santiago de Chile, 2001), No 6, pág. 63 y sigtes., y en "Derecho Administrativo. Su permanencia, contemporaneidad, prospectiva” cit., pág. 256.

${ }^{33}$ Sentencia del Tribunal Constitucional del Perú de 12 de mayo de 2006.

${ }^{34}$ Sentencia del Tribunal Constitucional del Perú de 5 de octubre de 2004.

${ }^{35}$ Sentencia de la Corte Suprema de Justicia de la Nación en el caso Madorrán, citado por Juan Carlos CASSAGNE - "Los grandes principios del Derecho Público Constitucional y Administrativo" (La Ley, Buenos Aires, 2015), pág. 49. 
amplitud ya que apunta a preservar la dignidad humana, alentar el desarrollo de los seres humanos, y ampliar y asegurar los derechos fundamentales de todos sin excepciones ${ }^{36}$.

A los efectos expositivos, intentaré la aproximación a su proyección a través de las tres señaladas dimensiones de la persona humana.

Por lo que refiere a la dimensión individual, cabe tener presente que una manifestación de este principio, que la Constitución uruguaya recoge en el art. 72, puede encontrarse en el art. 29 de la Convención Americana sobre Derechos Humanos, al tenor del cual los Estados no podrán:

a) suprimir el goce y ejercicio de los derechos y libertades reconocidos en la Convención o limitarlos en mayor medida que la prevista en ella;

b) limitar el goce y ejercicio de cualquier derecho o libertad que pueda estar reconocido de acuerdo con las leyes de cualquiera de los Estados parte o de acuerdo con otra convención en que sea parte uno de dichos Estados;

c) excluir otros derechos y garantías que son inherentes al ser humano o que se derivan de la forma democrática representativa de gobierno; $\mathrm{y}$

d) excluir o limitar el efecto que puedan producir la Declaración Americana de Derechos y Deberes del Hombre y otros actos internacionales de la misma naturaleza.

La jurisprudencia de nuestros países se ha pronunciado sobre estos deberes en situaciones especiales, tales como la de los adultos mayores, los trabajadores dependientes, los discapacitados o los privados de libertad, entre otros casos.

Así, la Sala Constitucional de la Corte Suprema de Justicia de Costa Rica ha entendido que "En cuanto al marco general de protección de la persona adulta mayor, la Constitución Política define al Estado Costarricense como un Estado social de Derecho, lo que implica garantizar un mínimo necesario para vivir de acuerdo con el reconocimiento de la dignidad de la persona humana como fundamento del orden constitucional mismo" ${ }^{37}$.

En similar sentido, ha afirmado que "La protección de la salud de los trabajadores es indispensable para garantizar el respeto a su dignidad", por lo que "el trabajador tiene derecho a ejecutar sus funciones en un ambiente apropiado, cuyas condiciones garanticen la protección de su derecho a la salud" ${ }^{38}$.

Igualmente, ha postulado que "las personas con discapacidad tienen los mismos derechos humanos y libertades fundamentales que otras personas, y estos derechos, incluido el de no verse sometidos a discriminación en razón de su incapacidad, dimanan de la dignidad y la igualdad que son inherentes a todo ser humano" ${ }^{39}$.

Asimismo, ha dicho que "Debe siempre tener presentela Administración penitenciaria que la condición de persona y la dignidad inherente a ella acompañará al ser humano en

36 Carlos E. DELPIAZZO - "Derecho Administrativo General" cit., volumen 2, segunda edición actualizada y ampliada, pág. 237.

${ }^{37}$ Sentencia de la Corte Suprema de Justicia de Costa Rica, Sala Constitucional, de 23 de mayo de 2014.

${ }^{38}$ Sentencia de la Corte Suprema de Justicia de Costa Rica, Sala Constitucional, de 16 de diciembre de 2016.

${ }^{39}$ Sentencia de la Corte Suprema de Justicia de Costa Rica, Sala Constitucional, de 23 de julio de 2014. 
todos y cada uno de los momentos de su vida, cualquiera que fuere la situación en que se encontrare" ${ }^{40}$.

En cuanto a la dimensión social, según lo reconocen los instrumentos internacionales y Constituciones americanas, la familia es acreedora de la protección estatal, la cual se expresa en un doble sentido: mediante la actuación y mediante la abstención.

Por un lado, a partir de la afirmación de la familia como sociedad natural y anterior a la sociedad civil -ya que la parte (la familia) es anterior al todo (la sociedad civil)- resulta con evidencia que el Estado tiene el deber de protegerla para la procura de sus derechos fundamentales ${ }^{41}$.

Por otro lado, la familia también tiene derecho al cuidado estatal a través de la abstención. En efecto, al Estado no le cabe introducirse en los aspectos que hacen al fuero personal de los integrantes de la familia, especialmente en lo que refiere a la aptitud para la trasmisión de la vida. Una injerencia estatal sustituyente de la familia en sus misiones naturales sería lesiva de la dignidad humana ${ }^{42}$.

Respecto a la dimensión trascendente, el principio "pro hómine" obliga, en general, a interpretar en forma favorable a la persona las normas que reconocen o amplían los derechos humanos y, a la inversa, en forma restrictiva los que imponen limitaciones o restricciones.

En particular, dicho principio impone el deber de respetar la conciencia de cada persona y, concretamente, la objeción de ella.

En Uruguay, a juicio del Tribunal de lo Contencioso Administrativo, "el reconocimiento del derecho de objeción de conciencia deriva de los derechos fundamentales del individuo, ya sea se lo relacione con el derecho a la libertad de conciencia, o con el derecho a la dignidad humana" ${ }^{43}$.

\section{IV) CONCLUSIÓN}

El neoconstitucionalismo contemporáneo revaloriza y acentúa la centralidad de la persona humana, como lo reconoce el art. $1^{\circ}$ de la Constitución alemana al proclamar que "La dignidad humana es intangible".

Como bien se ha puesto de manifiesto, asistimos a la instalación de nuevos paradigmas del Derecho público, entre los cuales el principio "pro homine", sustentado en la dignidad de la persona, refuerza la visión instrumental de las instituciones al servicio de los derechos fundamentales ${ }^{44}$.

Por eso, "Hoy en día en el mundo occidental se afirma lo que se ha llamado el Estado constitucional de Derecho, basado en la primacía de la Constitución o, mejor dicho, del

\footnotetext{
${ }^{40}$ Sentencia de la Corte Suprema de Justicia de Costa Rica, Sala Constitucional, de 12 de junio de 2015.

${ }^{41}$ Mariano R. BRITO - "El cuidado de la familia por el Estado y la procuración del bien común en nuestros países", en Rev. de Derecho Público (Santiago de Chile, 1995), No 57 - 58, pág. 170 y sigtes.

${ }^{42}$ Mariano R. BRITO - "Funciones del Estado en relación a la familia", en Américo PLA RODRIGUEZ y Ana María RANZETTI (Coordinadores) - "El Derecho y la Familia" cit., pág. 205 y sigtes.

${ }^{43}$ Sentencia del Tribunal de lo Contencioso Administrativo $N^{\circ} 586$ de 11 de agosto de 2015.

${ }^{44}$ Juan Carlos CASSAGNE - "Los grandes principios del Derecho Público Constitucional y Administrativo" cit., pág. 49 y sigtes.
} 
bloque de la constitucionalidad... Ese bloque de constitucionalidad reposa en la dignidad de la persona humana" ${ }^{45}$.

Y tal dignidad no deriva de ningún tratado, Constitución o ley sino que es innata a la naturaleza humana ${ }^{46}$, por lo que el aludido bloque de constitucionalidad comprende los derechos humanos reconocidos o no por la Constitución, contenidos o no en las convenciones internacionales ${ }^{47}$.

Siendo así, en el marco de las relaciones de la Administración (servicial) con los administrados (cada persona y sus comunidades intermedias), éstos ostentan una posición de centralidad que, no obstante, no lo exonera de deberes y responsabilidades. Pero son mayores los de la Administración como consecuencia de su propia naturaleza instrumental, de su ser para cada uno de los integrantes del cuerpo social a los que se debe vicarialmente.

\section{BIBLIOGRAFÍA}

ARDAO, Arturo - "El hombre en cuanto objeto axiológico", en "El hombre y su conducta. Ensayos filosóficos en honor de Risieri Frondizi” (UPRED, Buenos Aires, 1980), pág. 73 y sigtes.

BERCHESI, Bruno - “Objeción de conciencia. ¿Sabemos qué significa?”, en Rev. Jurídica La Ley Uruguay (Montevideo, 2010), Año III, No 3, pág. 446 y sigtes.

BLENGIO VALDES, Mariana - "El derecho al reconocimiento de la dignidad humana" (A.M.F., Montevideo, 2007).

BLENGIO VALDÉS, Mariana. "La dignidad humana como parámetro de interpretación en fuentes de Derecho Internacional de los Derechos Humanos y la Bioética. ¿La definición inexistente? Revista de Derecho Público No. 49. Montevideo, 2016, pp. 31 a 54. Disponible en: http:// www.revistaderechopublico.com.uy/revistas/49/archivos/Blengio49.pdf

BRITO, Mariano R. - "Libertad y autoridad del Estado", en A.A.V.V. - "Aspectos legales y socioeconómicos de la desregulación y privatización” (F.C.U., Montevideo, 1991), pág. 28 y sigtes.

BRITO, Mariano R. - "Derecho Administrativo. Su permanencia, contemporaneidad, prospectiva” (U.M., Montevideo, 2004).

BRITO, Mariano R. - "Principio de legalidad e interés público en el Derecho positivo uruguayo", en La Justicia Uruguaya, tomo XC, sección Doctrina, pág. 11 y sigtes.

BRITO, Mariano R. - "La dignidad humana como fundamento de nuestro Derecho Administrativo", en Carlos E. DELPIAZZO (Coordinador) - "Pasado y presente del Derecho Administrativo Uruguayo" (F.C.U., Montevideo, 2012) pág. 165 y sigtes.

BRITO, Mariano R. - "El Estado de Derecho en una perspectiva axiológica”, en Rev. Ius Publicum (Santiago de Chile, 2001), $\mathrm{N}^{\circ} 6$, pág. 63 y sigtes.

BRITO, Mariano R. - "El cuidado de la familia por el Estado y la procuración del bien común en nuestros países”, en Rev. de Derecho Público (Santiago de Chile, 1995), Nº 57 - 58, pág. 170 y sigtes.

BRITO, Mariano R. - "Funciones del Estado en relación a la familia", en Américo PLA RODRIGUEZ y Ana María RANZETTI (Coordinadores) - "El Derecho y la Familia” (F.C.U., Montevideo, 1998), pág. 205 y sigtes.

CAGNONI, José Aníbal - "La dignidad humana. Naturaleza y alcances", en CATEDRA UNESCO DE DERECHOS HUMANOS - "Dignidad Humana” (Montevideo, 2003), pág. 65 y sigtes., y en Rev. de Derecho Público (Montevideo, 2003), N 23, pág. 11 y sigtes.

CAGNONI, José Aníbal - "La primacía de la persona: el principio personalista”, en Rev. de Derecho Público (Montevideo, 2004), N 24, pág. 135 y sigtes.

${ }^{45}$ Mariano R. BRITO - "La dignidad humana como fundamento de nuestro Derecho Administrativo" cit., pág. 164.

${ }^{46}$ Jesús GONZALEZ PEREZ - "La dignidad de la persona humana y el Derecho Administrativo" cit., pág. 6 .

${ }^{47}$ Augusto DURAN MARTINEZ - "Neoconstitucionalismo y Derecho Administrativo" (La Ley Uruguay, Buenos Aires, 2012), pág. 845. 
CASSAGNE, Juan Carlos - "Los grandes principios del Derecho Público Constitucional y Administrativo" (La Ley, Buenos Aires, 2015).

CASSINELLI MUÑOZ, Horacio - "Libertad de asociación, personalidad jurídica y Poder Ejecutivo", en Rev. Derecho, Jurisprudencia y Administración, tomo 65, pág. 273 y sigtes.

CERVINI, Raúl - "El Derecho penal del enemigo y la inexcusable vigencia del principio de la dignidad de la persona humana", en Rev. de Derecho. Publicación arbitrada de la Universidad Católica del Uruguay (Montevideo, 2010), $\mathrm{N}^{\circ}$ 5, pág. 36 y sigtes.

CHAVEZ FERNANDEZ POSTIGO, José - "La dignidad como fundamento de los derechos humanos en las sentencias del Tribunal Constitucional peruano" (Palestra, Lima, 2012).

DELPIAZZO, Carlos E. - "Las dimensiones del administrado", en "Jornadas en homenaje al Prof. Dr. Mariano R. Brito organizadas por el Anuario de Derecho Administrativo" (U.M., Montevideo, 2014), pág. 227 y sigtes.

DELPIAZZO, Carlos E. - "Derecho Administrativo General" (A.M.F., Montevideo, 2015), volumen 1, segunda edición actualizada y ampliada.

DELPIAZZO, Carlos E. - "Derecho Administrativo General" (A.M.F., Montevideo, 2017), volumen 2, segunda edición actualizada y ampliada.

DELPIAZZO, Carlos E. - "Derecho Administrativo Especial" (A.M.F., Montevideo, 2010), volumen 2, segunda edición actualizada y ampliada.

DELPIAZZO, Carlos E. - "Derecho Administrativo Uruguayo" (Porrúa - UNAM, México, 2005).

DELPIAZZO, Carlos E. - "Dignidad humana y Derecho" (U.M., Montevideo, 2001).

DURAN MARTINEZ, Augusto - "Neoconstitucionalismo y Derecho Administrativo" (La Ley Uruguay, Buenos Aires, 2012).

GELSI BIDART, Adolfo - "La familia y el Derecho", en Américo PLA RODRIGUEZ y Ana María RANZETTI (Coordinadores) - "El Derecho y la Familia" (F.C.U., Montevideo, 1998), pág. 248 y sigtes.

GONZALEZ PEREZ, Jesús - "La dignidad de la persona" (Civitas, Madrid, 1986.

GONZALEZ PEREZ, Jesús - "La dignidad de la persona humana y el Derecho Administrativo" (Jurua, Curitiba, 2007).

GROS ESPIELL, Héctor - "La dignidad humana en los instrumentos internacionales de derechos humanos", en CATEDRA UNESCO DE DERECHOS HUMANOS - "Dignidad Humana" (Montevideo, 2003), pág. 9 y sigtes.

HANNA, Marta - "Recepción jurisprudencial de la objeción de conciencia", en Rev. de Derecho. Publicación arbitrada de la Universidad Católica de Uruguay (Montevideo, 2015), N 12, pág. 217 y sigtes.

JAVIER, Juvenal M. - "Reflexiones sobre la objeción de conciencia e ideario en el Uruguay a partir las leyes N ${ }^{\circ} 18.987$ y 18.473", en Rev. de Derecho Público (Montevideo, 2013), No 43, pág. 33 y sigtes.

LABORDE, Marcelo - "No sólo de derechos vive el hombre. Los deberes de las personas en el artículo 72 de nuestra Constitución", en Carlos E. DELPIAZZO (Coordinador) - "Pasado y presente del Derecho Administrativo Uruguayo" (F.C.U., Montevideo, 2012), pág. 185 y sigtes.

NAVARRO VALLS, Rafael y MARTINEZ TORRON, Javier - "Conflictos entre conciencia y ley (Iustel, Madrid, 2012), $2^{\mathrm{a}}$ edición revisada.

NAVARRO FLORIA, Juan G. - "El derecho a la objeción de conciencia" (Abaco, Buenos Aires, 2004).

REAL, Alberto Ramón - "Los principios generales de Derecho en la Constitución uruguaya" (Montevideo, 1965).

ROCCA, María Elena - "Toda nuestra Constitución reposa sobre la noción de persona", en Rev. de Derecho Público (Montevideo, 2004), $\mathrm{N}^{\circ}$ 24, pág. 139 y sigtes.

RODRIGUEZ ARANA MUÑOZ, Jaime - "Etica, Poder y Estado" (RAP, Buenos Aires, 2004).

SAGÜES, Néstor - "Dignidad de la persona e ideología constitucional", en Rev. de Derecho Constitucional y Político (Montevideo, 1996), tomo XII, Nº 72, pág. 679 y sigtes.

SANCHEZ, Alberto M. - "La objeción de conciencia en el agente estatal", en Víctor HERNANDEZ MENDIBLE - "Desafíos del Derecho Administrativo Contemporáneo. Conmemoración Internacional del Centenario de la Cátedra de Derecho Administrativo en Venezuela" (Paredes, Caracas, 2009), tomo I, pág. 283 y sigtes.

SECO, Ricardo Francisco - "Un contenido para los términos dignidad de la persona humana. Aportes desde el Derecho del trabajo y el pensamiento social cristiano", en Rev. Derecho Laboral (Montevideo, 2010), tomo LIII, No 239 , pág. 459 y sigtes.

SOTO KLOSS, Eduardo - "Derecho Administrativo" (Editorial Jurídica de Chile, Santiago, 1996), tomo I.

SOTO KLOSS, Eduardo - "La primacía de la persona humana, principio fundamental del Derecho público chileno", en Estudios Jurídicos en memoria de Alberto Ramón Real (F.C.U., Montevideo, 1996), pág. 507 y sigtes.

YEPES STORK, Ricardo - "Fundamentos de Antropología" (EUNSA, Pamplona, 1996). 